\title{
Heavy School Bags and Musculoskeletal System Problems among School-Going Children
}

\author{
Minakshi Chaudhari ${ }^{1} \cdot$ Sushma Kumari Saini ${ }^{1}$ (D) Bhavneet Bharti $^{2} \cdot$ Nirmal Raj Gopinathan ${ }^{3} \cdot$ Kavita Narang $^{1}$
}

Received: 16 January 2021 / Accepted: 7 May 2021 / Published online: 18 June 2021

(C) Dr. K C Chaudhuri Foundation 2021

To the Editor: School bag plays an important role in children's education. Regular use of heavy school bags and inappropriate carrying method put children at the risk of musculoskeletal problems [1]. The recommended school bag weight is less than $10 \%$ of child's body weight [2].

In this study, a total of 694 children from class 1 st to 10 th were selected from two schools. Weight of school bags and children was recorded by using weighing machine. Bag strap length, torso length of children, length and breadth of school bag, shoulder size of children were measured by using measuring tape to know the appropriate strap length and bag size according to the size of child. They were observed for body posture (stooping or upright), bag carrying style (carrying on one strap or both). Children from 5th to 10th class were interviewed for musculoskeletal problems (Nordic Musculoskeletal Questionnaires) [3].

There was over all high prevalence $(80 \%, 555$ children) of heavy school bag. Among them 55\% were carrying heavy school bags (> $10 \%$ of body weight of child) and $19.2 \%$ were carrying very heavy school bag ( $>20 \%$ of body weight). The prevalence of heavy school bags was observed in all the classes. The highest prevalence was observed among 5 th class students $(98.6 \%)$. Eighth class onward the percentage of heavy school bags started reducing i.e., $72.4 \%$ (8th class), $51.1 \%$ (9th class), and 46.5\% (10th class).

Further, $58.3 \%$ children were having musculoskeletal problems. Musculoskeletal problems of children with heavy

Sushma Kumari Saini

sushmadrsaini@gmail.com

1 National Institute of Nursing Education, Post Graduate Institute of Medical Education and Research (PGIMER), Sector 12, Chandigarh 160012, India

2 Department of Pediatrics, Government Medical College Hospital, Mohali, Punjab, India

3 Department of Orthopedics, PGIMER, Chandigarh, India bags were 3.295 times higher than not carrying heavy school bags. Other related factors were carrying bag on one strap, long strap, big-size bag and faulty posture while carrying bag. Hence, it is recommended that the school management should implement strategies to reduce weight of school bag in collaboration with teachers, parents, and children. Limitations of the present study were related to generalization of findings as the data were collected from two schools only.

\section{Declarations}

Conflict of Interest None.

\section{References}

1. Balamurugan J. School bags and musculoskeletal pain among elementaryschool children in Chennai city. In: International Journal of Medical Science and Clinical Invention. 2014. Available at: https://www.researchgate.net/publication/306099306_School_ Bags_and_Musculoskeletal_Pain_Among_Elementary_School_ Children_In_Chennai_City. Accessed on 6 Apr 2019.

2. Rai A. Back problems due to heavy backpacks in school children. In: IOSR Journal of Humanities and Social Science. 2013. Available at: www.iosrjournals.org. Accessed on 4 Feb 2019.

3. Crawford JO. The Nordic musculoskeletal questionnaire. In: Occupational Medicine. 2007. Available at: https://academic.oup. com/occmed/article-lookup/https://doi.org/10.1093/occmed/ kqm036. Accessed on 4 Feb 2019.

Publisher's Note Springer Nature remains neutral with regard to jurisdictional claims in published maps and institutional affiliations. 